\title{
Rutin Attenuates Hepatotoxicity in High-Cholesterol-Diet-Fed Rats
}

\author{
Shakir D. AlSharari, ${ }^{1}$ Salim S. Al-Rejaie, ${ }^{1}$ Hatem M. Abuohashish, ${ }^{1,2}$ \\ Mohamed M. Ahmed, ${ }^{1}$ and Mohamed M. Hafez ${ }^{1}$ \\ ${ }^{1}$ Department of Pharmacology and Toxicology, College of Pharmacy, King Saud University, P.O. Box 2457, Riyadh 11451, Saudi Arabia \\ ${ }^{2}$ Department of Biomedical Dental Sciences, College of Dentistry, University of Dammam, Dammam 31441, Saudi Arabia
}

Correspondence should be addressed to Mohamed M. Hafez; mohhafez_2000@yahoo.com

Received 7 December 2015; Revised 29 February 2016; Accepted 10 March 2016

Academic Editor: Reiko Matsui

Copyright (C) 2016 Shakir D. AlSharari et al. This is an open access article distributed under the Creative Commons Attribution License, which permits unrestricted use, distribution, and reproduction in any medium, provided the original work is properly cited.

\begin{abstract}
Background and Objective. High-cholesterol diet (HCD) intends to increase the oxidative stress in liver tissues inducing hepatotoxicity. Rutin is a natural flavonoid (vitamin p) which is known to have antioxidative properties. The aim of the present study was to investigate the potential effects of Rutin on hypercholesterolemia-induced hepatotoxicity in rats. Materials and Methods. Male Wistar rats were divided into four groups: G-I control, G-II Rutin, G-III HCD, and G-IV Rutin + HCD. The liver functions and lipid profile were used to evaluate the HCD-induced hepatotoxicity. Quantitative real time-PCR was carried out to evaluate the expression levels of genes in TGF- $\beta /$ Smad signaling pathway. Results. Rutin in combination with HCD showed a significant protective effect against hepatotoxicity. HCD caused significant increase in the mRNA expression of transforming growth factor beta (TGF- $\beta$ ), Mothers Against Decapentaplegic Homolog 2 (Smad-2), Mothers Against Decapentaplegic Homolog 4 (Smad-4), Bcl2-binding component 3 (Bbc3), caspase-3, P53 and Interleukin-6 (IL-6) and decrease in the expression levels of Cyclin depended kinase inhibitor (P21) and Interleukin-3 (IL-3) in hepatic cells. Conclusion. TGF- $\beta / S m a d$ signaling pathway is involved in HCDinduced hepatotoxicity and Rutin inhibits the hepatotoxicity via suppressing this pathway. Therefore, Rutin might be considered as a protective agent for hepatotoxicity.
\end{abstract}

\section{Introduction}

Nonalcoholic steatohepatitis (NASH) is a form of chronic liver disease and a part of nonalcoholic fatty liver disease (NAFLD), which may lead to cirrhosis and hepatocellular carcinoma (HCC) [1-7]. The prevalence of NAFLD has significantly increased worldwide with the increase of obesity $[4,8]$. Investigating the mechanisms of NAFLD may help in finding the strategies against this disease [9]. Oxidative stress induced by high-cholesterol diet can mediate a variety of cellular responses leading to diverse outcomes such as apoptosis [10, 11], which is involved in NASH causation [12].

Apoptosis occurs in many human liver disorders $[13,14]$ and can trigger cell repair, inflammation, regeneration, and fibrosis [15]. Liver fibrosis may result in cirrhosis and endstage liver disease $[16,17]$. The uncontrolled hepatocyte apoptosis may be a central mechanism, triggering liver fibrogenesis [18]. The hepatocyte is specific genetic disruption of the antiapoptotic member of the Bcl-2 family Bcl-xL resulting in hepatocyte apoptosis and liver fibrotic responses [19]. Engulfment of apoptotic bodies by hepatic stellate cells (HSCs) stimulates fibrogenic activity [20]; and the DNA from apoptotic hepatocytes can act as an important mediator of HSC activation and differentiation [21].

The TGF- $\beta$ cytokine is involved in cell survival, proliferation, differentiation, and angiogenesis $[13,14]$. TGF- $\beta$ binding to its receptor causes recruitment and phosphorylation of other TGF- $\beta$ receptors that could activate the Smad pathways. The initiation of TGF- $\beta /$ Smad signaling pathway started by the formation of heteromeric receptor complexes [22, 23] that lead to phosphorylation of Smad-2 and Smad-3 and then the formation of a complex with Smad4. The phosphorylated Smad-2 and Smad-3 associate with Smad-4 and then enter the nucleus to regulate gene transcription [17]. Furthermore, Smad proteins are mediators for the TGF- $\beta$-induced 
apoptosis [24]. Transforming growth factor- $\beta 1$ is formed mainly by fibroblast and contributes to fibrosis development, hypertrophy, and apoptosis [25]. The role of TGF- $\beta / S m a d$ signaling in hepatocytes in the development of NASH is not well understood and its role in metabolic disease is still limited. In liver, TGF- $\beta$ signaling participates in fibrogenic response through hepatic stellate cell activation [26]. In chronic liver diseases, HSCs are primary target for active $T G F-\beta$, and thus it plays a role in progression of fibrosis in advanced NAFLD. Procollagen- $\alpha_{1}$ and procollagen- $\alpha_{2}$, tissue inhibitor of metalloproteinase-1 and metalloproteinase-2 (TIMP-1 and TIMP-2), and plasminogen activator inhibitor1 (PAI-1) are identified as direct TGF- $\beta$ target genes in HSCs [27-29]. However, the transcriptional activation of myofibroblast markers $\alpha$-smooth muscle actin (SMA) and connective tissue growth factor (CTGF) is induced in a TGF$\beta$-independent manner. Instead, TGF- $\beta$ signaling is required for $\alpha$-SMA organization and stress-fiber formation [30].

Heme oxygenase-1 (HO-1) has protective activity against acute and chronic liver injury [31] and is regulated by $N r f 2$ transcription factor [32]. Studies found that during hepatic injury, induced by oxidative stress, $\mathrm{HO}-1$ and Nrf2 were downregulated and were associated with $N F-\kappa B$ upregulation $[33,34]$. The Rutin administration results in Nrf2, HO- , and $N F-\kappa B$ overexpression. Rutin acts as $\mathrm{HO}-1$ inducer in liver ischemia-reperfusion injury rat model [35]. The nuclear translocation of HO-1 could regulate the genes responsible for cytoprotection against oxidative stress [36]. The release of ROS is known to activate inhibitory kappa-B kinase which causes phosphorylation of $I \kappa B$. Release of free $N F-\kappa B$ enhances the inflammatory cytokines [37] and suppresses the antioxidant genes by downregulating $\mathrm{Nrf}-2 / \mathrm{HO}-1$ pathway. Rutin is capable of inhibiting $N F-\kappa B$ and activating the Nrf-2 pathway. Sirtuin 1 (Sirt1), a member of sirtuin proteins family, downregulation is associated with high insulin resistance and loss in mitochondrial biogenesis cells [38]. High-cholesterol diet decreases genes expression levels that are involved in muscle mitochondrial biogenesis and function such as Sirt1, peroxisome proliferator-activated receptor coactivator1 (PGC-1), and mitochondrial transcription factor A (Tfam) [39]. Rutin increases the expression levels of Sirt1, $P G C-1$, and Tfam in skeletal muscle and brain of mice, which lead to increase in muscle mitochondrial biogenesis and function [40]. Therefore the antiobesity property of Rutin might be associated with Rutin-mediated muscle mitochondrial changes.

Flavonoids are polyphenolic compounds found in plants and have an important role in detoxification of free radicals [41]. Rutin is a flavonoid glycoside that possessed different protective effects [42, 43] against lipid peroxidation and oxidative-stress-mediated diseases [44]. Therefore, the present study was aimed to investigate the preventive effect of Rutin against HCD-induced hepatotoxicity in rats through studying genes expression in the TGF- $\beta / S$ mad pathways.

\section{Materials and Methods}

2.1. Animals. Forty male Wistar albino rats weighing between 80 and $180 \mathrm{~g}$ were obtained from the Animal Care Center,
College of Pharmacy, King Saud University, Riyadh, Saudi Arabia. The animals were acclimatized to laboratory condition ten days prior to the experiment. They were fed on Purina rat chow diet (manufactured by Grain Silos \& Flour Mills Organization, Riyadh, Saudi Arabia) and water on a free access basis and were maintained under standard conditions of temperature $\left(22 \pm 1^{\circ} \mathrm{C}\right)$, humidity (50-55\%), and $12 \mathrm{~h}$ light/dark cycles. All methods including euthanasia procedure were conducted in accordance with guide for care and use of laboratory animals, Institute for Laboratory Animal Research, National Institute of Health (NIH publication number 80-23; 1996), and they have been approved by Research Ethics Committee of Excremental Animal Care Center, College of Pharmacy, King Saud University, Riyadh, Saudi Arabia.

2.2. Diets. Diets were prepared in pellet form by adding $0.2 \%$ Rutin (RT) (powder, Sigma, USA) or $1 \%$ cholesterol $+0.5 \%$ cholic acid (HCD) or $0.2 \%$ RT $+1 \%$ cholesterol $+0.5 \%$ cholic acid (RT + HCD) in rat chow powder. Rat chow was used as normal diets and was prepared weekly and shade dried. Food intake g/day was calculated daily for each group to the end of experiments.

2.3. Experimental Design. The animals were randomly divided into 4 groups of 10 rats in each as follows: Group I, control; Group II, RT; Group III, HCD; and Group IV, RT + HCD. The experimental diets were fed on a free access basis for 6 consecutive weeks. At end of the experiment, rats were weighed and sacrificed by decapitation and the trunk blood was collected in heparinized tubes. Rats livers were rapidly excised, weighed, and kept at $-80^{\circ} \mathrm{C}$ till analysis. Plasma samples were collected after centrifugation and stored at $-20^{\circ} \mathrm{C}$ till analysis.

2.4. Bioassay Measurements. Plasma levels of ALT, AST, TG, TC, HDL, and LDL were estimated by using commercially available diagnostic kits (Human, Wiesbaden, Germany).

\subsection{Measurement of Caspase-3 Activity in the Liver Tissues.} The caspase- 3 activity was measured in liver tissues by using colorimetric assay ab39401 (Abcam, Cambridge, MA 021391517, USA) kit according to the manufacturer instructions. In brief, $0.2 \mathrm{mg}$ of liver tissues was not homogenized completely in $50 \mu \mathrm{L}$ cell lysis buffer on ice for 10 minutes. After centrifugation, the protein concentrations were adjusted to 50-200 $\mu \mathrm{g}$ protein per reaction. Fifty microlitres of caspase reaction mix containing $10 \mathrm{mM}$ DTT was added to each well. Two hundred micromolars of DEVD- $p$-NA substrate was added, and then after $120 \mathrm{~min}$ incubation at $37^{\circ} \mathrm{C}$ the plate was measured at $405 \mathrm{~nm}$. Fold increase in caspase- 3 activity can be determined by comparing sample (treated) results with the level of the untreated control.

2.6. Quantitative Real-Time Polymerase Chain Reaction ( $q R T$ PCR). Gene expression levels of TGF- $\beta$, Smad-2, Smad4, caspase-3, P21, P53, IL-3, and IL-6 were detected in liver tissues by quantitative real-time PCR. Total RNA were 
TABle 1: Primer sequence used in this study.

\begin{tabular}{|c|c|c|}
\hline Gene name & Forward primer & Reverse primer \\
\hline$T$ TGF- $\beta$ & $5^{\prime}$-TGCCTGACGGTCAGGTCA- $3^{\prime}$ & $5^{\prime}$-CAGGAAGGAAGGCTGGAG-3' \\
\hline Smad-2 & $5^{\prime}$-CCATCCCCGAGAACACTAACTT-3' & 5'-TGGTGGTCGCTAGTTTCTCCAT-3' \\
\hline Smad-4 & $5^{\prime}$-АССААСТТССССААСАТТССТ-3' & $5^{\prime}$-ACTATGGCTGCCTGCCAGAA-3' \\
\hline Caspase-3 & $5^{\prime}$-AAATTCAAGGGACGGGTCATG-3' & $5^{\prime}$-GAGCTTGTGCGTACAGTT- $3^{\prime}$ \\
\hline$B b c 3$ & $5^{\prime}$-AGCCAAACCTGACCACTAGC-3' & $5^{\prime}$-CCAGATGAAGGTGAGGCAGG-3' \\
\hline P53 & $5^{\prime}$-CACCATGAGCGTTGCTCTGAT-3' & 5'-GATTTCCTTCCACCCGGATAA-3' \\
\hline$P 21$ & $5^{\prime}$-GAGAACTGGGGAGGGCTTTC-3' & 5'-TCCTGAGCCTGTTTCGTGTC-3' \\
\hline$I L-3$ & 5'-TTGTATTCCTGCAGCTGCGA-3' & $5^{\prime}$-GGGCTGAGGTGGTCTAGAGA-3' \\
\hline$I L-6$ & $5^{\prime}$-ATCTGCССTTCAGGAACAGC-3' & 5'-AGCCTCCGACTTGTGAAGTG-3' \\
\hline$\beta$-actin & $5^{\prime}$-TGCCTGACGGTCAGGTCA- $3^{\prime}$ & $5^{\prime}$-CAGGAAGGAAGGCTGGAAG-3' \\
\hline
\end{tabular}

extracted from liver tissues using RNA Mini Kit (Bioline, Taunton, USA) according to the manufacturer's protocol. The quantity and integrity of total RNA were characterized using a UV spectrophotometer (Nanodrop 8000, Thermo Scientific, USA) and ethidium bromide stained agarose gel. The isolated RNA has an A 260/280 ratio of 1.9-2.0. First-strand cDNA was synthesized from $1 \mu \mathrm{g}$ of total RNA by reverse transcription with a SuperScript ${ }^{\mathrm{TM}}$ first-strand synthesis system kit (Invitrogen, CA, USA), according to the manufacturer's instructions. Quantitative real-time PCR using $\Delta \Delta \mathrm{CT}$ method was done according to our previous study [10]. $\beta$-actin gene is used as internal control. All primers used in this study were listed in Table 1.

2.7. Statistical Analysis. Differences between obtained values (mean \pm SEM, $n=10$ ) were carried out by one way analysis of variance followed by the Tukey-Kramer multiple comparison. The differences were considered statistically significant at $P<$ 0.05 .

\section{Results}

As in our previous study [10], the liver enzymes, ALT and AST plasma levels, were used as biochemical markers for early acute hepatotoxicity. Rats fed with HCD for 6 weeks had significant increase in ALT (Figure 1(a)) and AST (Figure 1(b)) levels $(P<0.001)$ compared to control and HCD + Rutin groups. Rutin supplementation alone showed no significant changes in biochemical markers. However, administration of Rutin in combination with HCD resulted in reversal of hepatic damage biomarker induced by HCD to the values as in control group. These reversal changes were significant compared to HCD group.

The effect of HCD on the body and liver weights as well as the food intake during the experiment was shown in Figure 2. HCD significantly increased the liver weight (Figure 2(a)) and the body weight (Figure 2(b)) compared to control and Rutin groups. On the other hand there was no significant difference observed in food intake during experiment among all studied groups (Figure $2(\mathrm{c})$ ). The supplementation of $0.2 \%$ Rutin or $1 \%$ cholesterol $+0.5 \%$ cholic acid (HCD) or $0.2 \% \mathrm{RT}+1 \%$ cholesterol $+0.5 \%$ cholic acid (RT + HCD) to the food did not influence the food intake among all groups.
The effects of HCD on the lipid parameters including TG, TC, HDL, and LDL levels were shown in Figure 3. Highcholesterol diet significantly increased plasma levels of TG (Figure 3(a)), TC (Figure 3(b)), and LDL (Figure 3(c)) by $48 \%, 89 \%$, and $67 \%$, respectively, and significantly decreased the HDL (Figure 3(d)) levels by 17\% compared to control group. Rutin supplementation in combination with HCD significantly increase TG, TC, and LDL levels and insignificantly decreased plasma levels of HDL compared to control group. On the other hand there were no significant differences observed in the plasma lipids levels (TG, TC, HDL, and LDL) in RT group compared to control group.

The expression levels of TGF- $\beta$, Smad-2, Samd-4, P21, caspase-3, and P53 genes were studied in rats hepatic cells to investigate whether HCD stimulates the TGF- $\beta 1$ signaling cascade that leads to liver fibrosis and apoptosis. The effects of HCD, Rutin, and their combination on TGF- $\beta 1$, Smad-2, and Smad-4 expression levels were shown in Figure 4. In HCD group, the expression levels of TGF- $\beta$ (Figure 4(a)), Smad2 (Figure 4(b)), and Smad-4 (Figure 4(c)) were significantly increased by 8-, 8.5-, and 5.3-fold, compared to the control group. On the other hand, administration of Rutin in combination with HCD induced a significant repair of the HCDinduced alteration in the gene expression of TGF- $\beta$, Smad-2, and Smad-4 compared to the HCD group expression levels.

Figure 5 shows the effect of HCD, Rutin, and their combination on the expression level of caspase-3 (a), P53 (b), $P 21$ (c), and $B b c 3$ (d) and on the caspase-3 activity (e) in rat liver tissues. High-cholesterol diet resulted in significant increases in expression levels of caspase-3, $P 53$, and $B b c 3$ by 6.2-, 5.3-, and 6.8-fold, respectively, compared to the control group. Interestingly, administration of Rutin in combination with HCD resulted in a complete reversal change of caspase$3, P 53$, and $B b c 3$ induced by HCD to the normal expression levels as in control group. The activity of caspase- 3 cleavage in liver tissues of control rats which feed on rat chow was hardly detectable, while a significant increase by $289 \%$ and $192 \%$ in the levels of cleavage caspase- 3 was observed in the HCDfed rat compared to control and Rutin group, respectively. The Rutin in combination with HCD significantly decreased the levels of cleavage caspase- 3 by $62 \%$ compared to HCD group. On the other hand, HCD suppressed the expression level of $P 21$ by 2.85 -fold, while administration of Rutin 


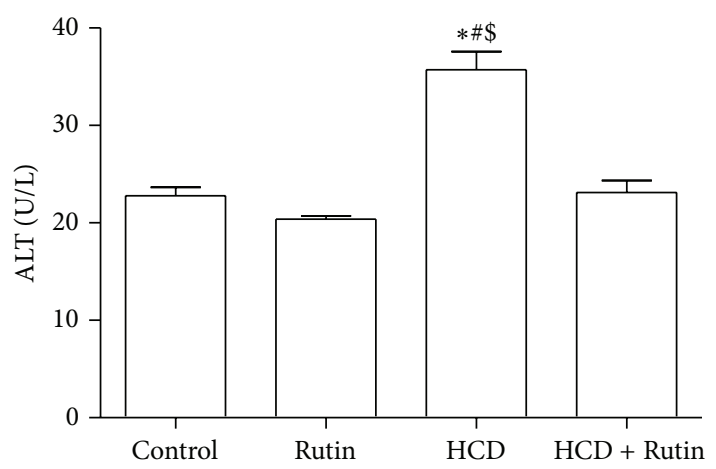

(a)

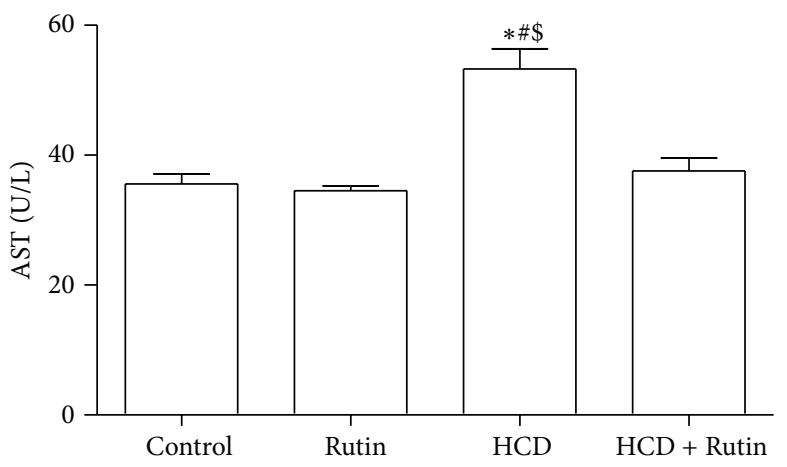

(b)

FIgURE 1: The effect of HCD, Rutin, and their combination on the plasma levels of ALT (a) and AST (b) in rats. Data are presented as mean \pm SEM $(n=10) . *$, \#, and $\$$ indicate significant change from control, Rutin, and HCD + Rutin, respectively, at $P<0.05$ using ANOVA followed by Tukey-Kramer as a post-ANOVA test.

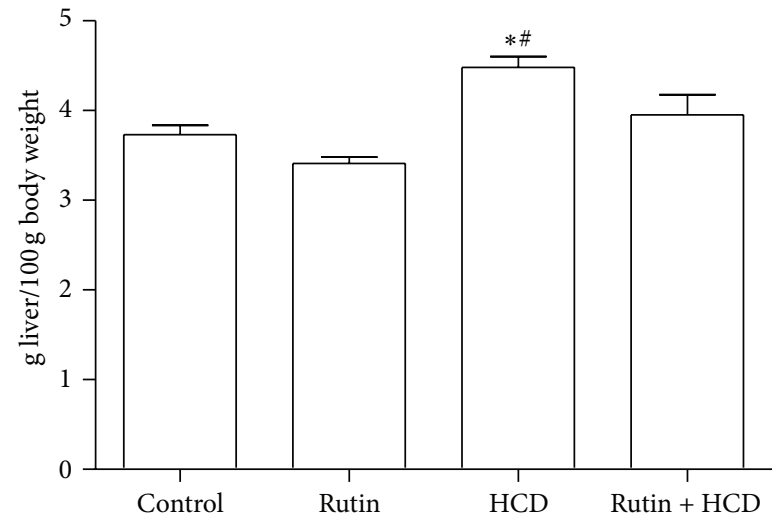

(a)

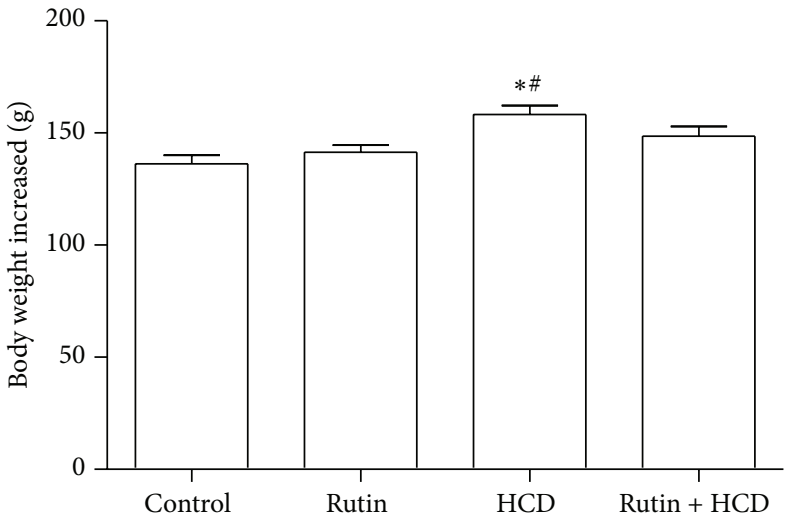

(b)

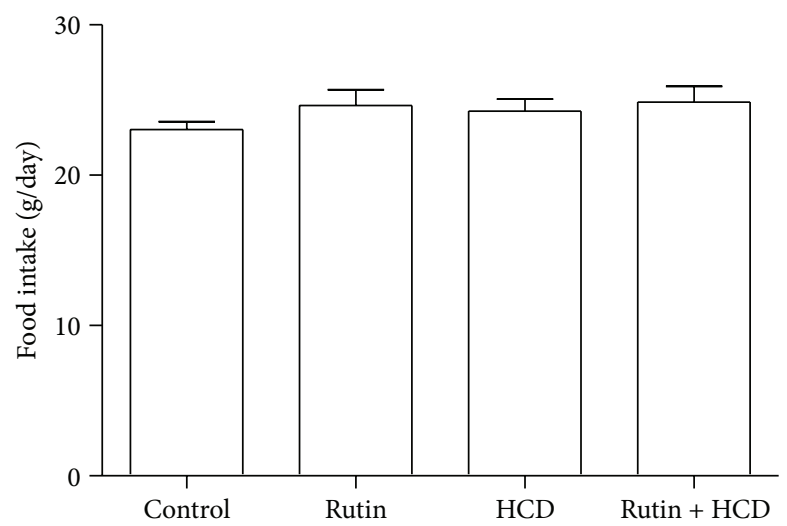

(c)

Figure 2: The effect of HCD, Rutin, and their combination on the liver weight (a), body weight (b), and food intake (c) in rats. Data are expressed as mean \pm SEM $(n=10)$. * and \# indicate significant change from control, Rutin, respectively, at $P<0.05$ using ANOVA followed by Tukey-Kramer as a post-ANOVA test.

in combination with $\mathrm{HCD}$ resulted in a complete reversal change of $P 21$ induced by HCD to values as in control group.

Figure 6 shows the effects of HCD, Rutin, and their combination on the expression level of $I L-3$ (a) and $I L-6$ (b) in rat liver tissues. The expression level of $I L-6$ was significantly increased by 5.8 -fold in rats fed with HCD compared to control group. On the other hand, rats fed with HCD had decreases in the expression levels of IL-3 by 3 -fold compared to control group. Interestingly, supplementation of Rutin in combination with HCD resulted in a complete reversal change of $I L-6$ and $I L-3$ induced by HCD to the normal values as in control group. 


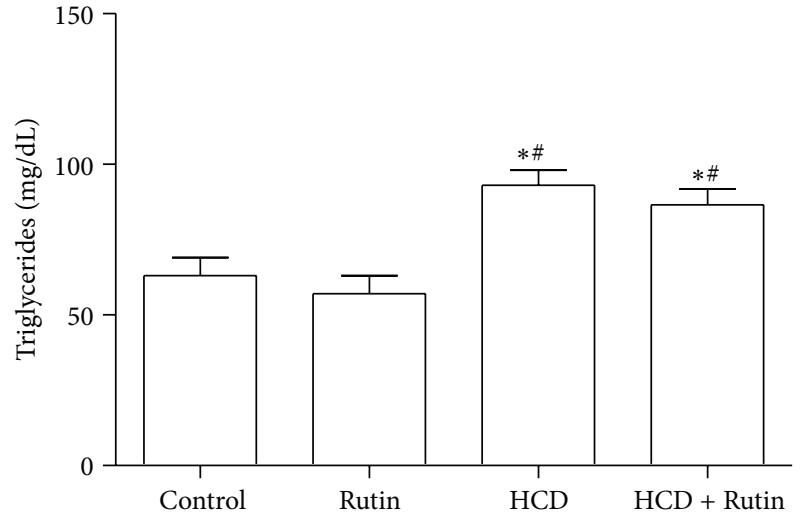

(a)

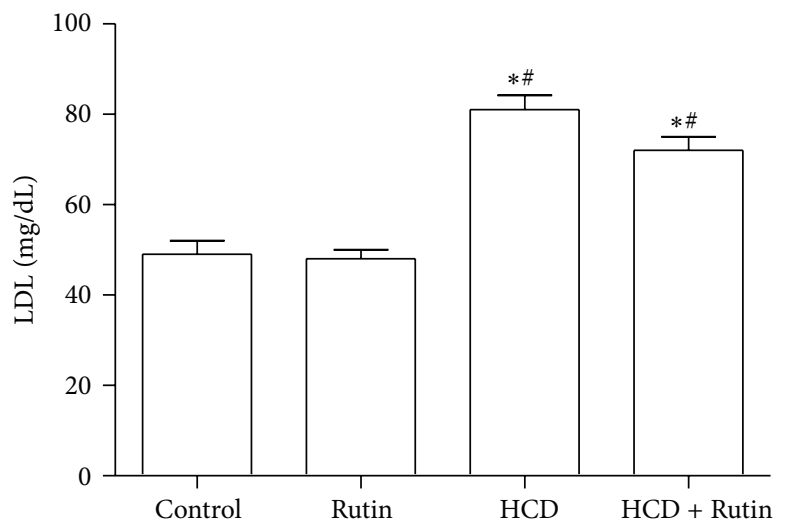

(c)

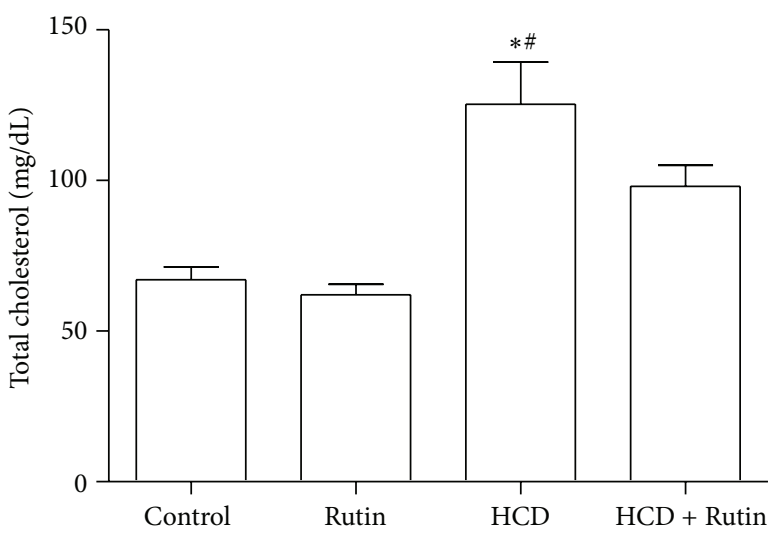

(b)

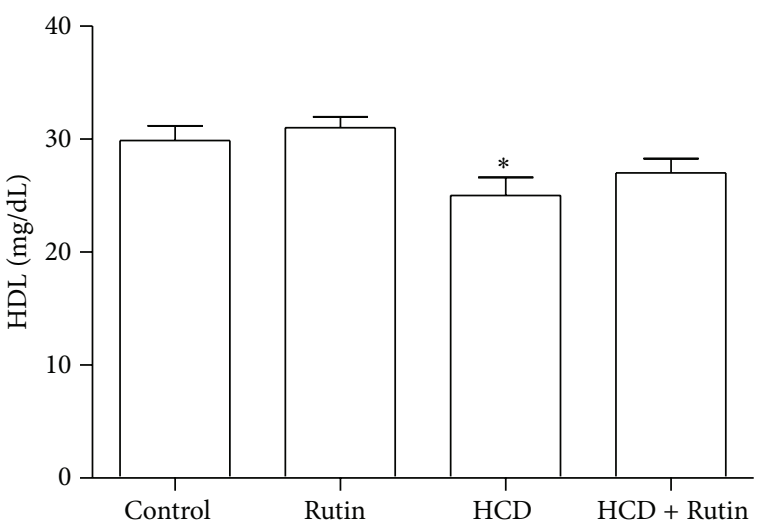

(d)

Figure 3: The effect of HCD, Rutin, and their combination on the plasma levels of triglyceride (a), total cholesterol (b), high-density lipoprotein (c), and low-density lipoprotein $(\mathrm{d})$ in rats. Data are presented as mean \pm SEM $(n=10)$. * and \# indicate significant change from control and Rutin groups, respectively, at $P<0.05$ using ANOVA followed by Tukey-Kramer as a post-ANOVA test.

\section{Discussion}

Obesity, hypertriglyceridemia, and/or hypercholesterolemia are the common causes for many diseases such as cardiovascular [45] and liver diseases [46, 47]. Rat fed with HCD can be used as model of the human obesity syndrome [48]. In liver disease, cell repair, inflammation, regeneration, and fibrosis may all be triggered by apoptosis [13, 14]. Nonalcoholic fatty liver disease can end in cirrhosis and hepatocellular carcinoma [6]. The present study examined the hepatoprotective effect of Rutin against hepatotoxicity induced by HCD in rat model. The HCD caused hepatotoxicity through increasing liver enzymes, ALT and AST. In agreement with earlier studies, the elevated ALT and AST levels are attributed to hepatic damage that may contribute to oxidative stress unbalance [45, 49]. Earlier it is reported that Rutin has potential to reduce the oxidative stress in liver, kidney, and brain tissues of rats [50]. As a result of Rutin supplementation, ALT and AST levels were lowered leading to decrease in the hepatic damage caused by HCD feedings. The present study showed that Rutin can protect hepatocyte against the toxicity induced by HCD.

High-cholesterol diet leads to dyslipidemic syndrome and hyperlipidemia that is characterized by increase in TG and decrease in HDL-cholesterol [51]. In the current study, high-cholesterol diet led to TG increase and HDL-cholesterol decrease. The accumulation of excess triglycerides in hepatocytes forms steatotic droplets in NAFLD [52, 53]. The hyperlipidemia, hypertriglyceridemia, and the decreasing in HDL-cholesterol increase the risk of NAFLD [54]. In the present study, Rutin supplement ameliorated the effect of HCD by lowering TC, TG, and LDL levels. Similarly, Rutin decreased the lipid in hypercholesterolemic rats by reducing the activity of 3-hydroxy-3-methyl-glutaryl-CoA reductase [55]. Also, Rutin has a strong ability to chelate multivalent metal ions, especially zinc, calcium, and iron [56].

The immunoregulatory cytokine such as IL-6 is a multifunctional cytokine that regulates some biological process and may play essential role ranging from inflammation to host defense toward tissue injury [57]. Interleukin-6 with TNF $\alpha$ stimulates hepatic lipogenesis [58], impairs insulin signaling [59], and can trigger different key steps in insulin signaling pathway [60]. In the current study, HCD increased IL-6 expression level in NAFLD compared to control group. Similar study found that TNF- $\alpha$ and IL-6 levels were significantly increased in NAFLD patients [61]. Interleukin6 helps the hepatic survival by stimulating liver recovery and gives hepatoprotection $[62,63]$. Binding of $I L-6$ to its 


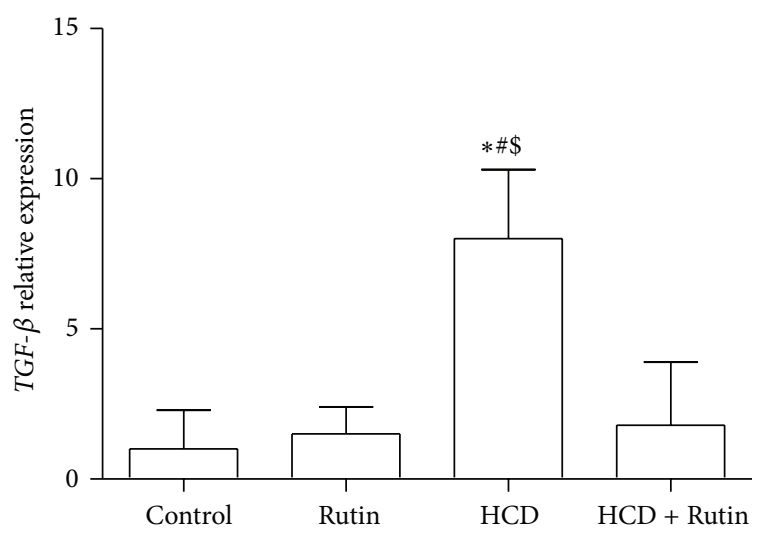

(a)

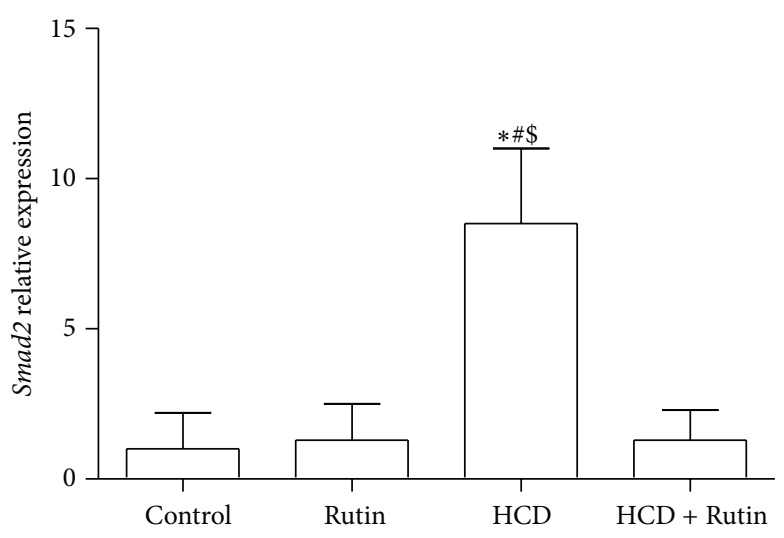

(b)

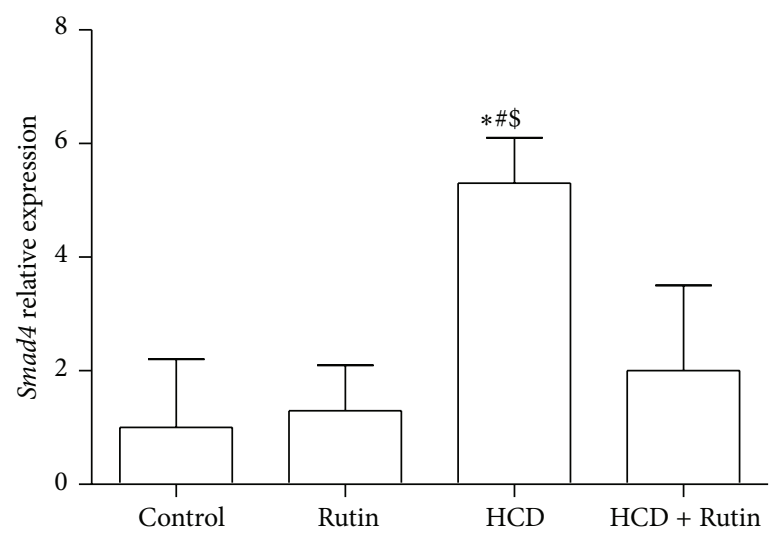

(c)

Figure 4: The effect of HCD, Rutin, and their combination on the levels of TGF- $\beta$ (a), Smad-2 (b), and Smad-4 (c) expression level in rats liver tissues. Data are presented as mean $\pm \operatorname{SEM}(n=10) . *$, \#, and $\$$ indicate significant change from control, Rutin, and HCD plus Rutin, respectively, at $P<0.05$ using ANOVA followed by Tukey-Kramer as a post-ANOVA test.

receptor $(I L-6 R)$ prompts STAT3 pathway activation through binding to glycoprotein 130 (gp130). IL-6 acts as both proand anti-inflammatory cytokines and may mediate liver damage through different pathways. Elevated levels of $I L$ 6 are associated with disease states [64]. The soluble form of $I L-6 R$ in addition to membrane-bound receptor binds to IL-6 and prolongs its plasma half-life [65]. The soluble $I L-6 R$ has roles in cellular proliferation, differentiation, and activation of inflammatory responses [66,67]. In the current study, downregulated IL-6 expression level as a result of Rutin administration may lead to the attenuation of the dietinduced hepatotoxicity. Rutin possesses anti-inflammatory effect by downregulating $I L-6$ and TGF- $\beta 1$, which promotes extracellular matrix deposition and fibrosis [68]. It has been reported that Rutin produced anti-inflammatory effects by inhibiting proinflammatory cytokines in adjuvant-induced arthritis in rats [69].

IL-3 cytokine is important for cell survival, proliferation, and differentiation $[70,71]$ and participates in the response to stress [72]. IL-3 may be involved in alcohol induced liver injury with unclear role [73]. In the current study, significant reduction in $I L-3$ was observed following HCD feeding. The downregulation of $I L-3$, in HCD group, suggested the potential involvement of $I L-3$ in HCD-induced liver injury.
Recent study reported that the downregulation in IL-3 is associated with liver injury [74]. Similarly, Sheng et al. found a decrease in level of $I L-3$ in rat treated with Dioscorea bulbifera [74].

TGF- $\beta 1$ gene downregulation can suppress the liver fibrosis and apoptosis [75]. In the present study, HCD expresses high levels of hepatic TGF- $\beta 1$, Smad-2, and Smad-4 gene expression. These findings suggest the possible involvement of TGF- $\beta 1$, Smad-2, and Smad-4 genes in the regulation of hepatotoxicity process. Phosphorylation of Smad-2 and Smad- 3 by TGF- $\beta$ leads to Smad- 4 translocation into nucleus. In the nucleus, Smad-4 functions to regulate transcription of target genes including $P 21$ and proapoptotic Bcl-2 family [76]. TGF- $\beta 1 /$ Smad-2 signaling is responsible for insulin regulation and pancreatic $\beta$-cell function [77]. The effects of Smad genes on obesity and type 2 diabetes are not well understood. In the current study, the HCD increased Smad2 and Smad-4 expression levels. The role of Smad-2 in liver fibrosis is less well characterized but in comparison with Smad-3 seems to regulate a distinct set of target genes $[78,79]$. The combination of Rutin with HCD has downregulated the Smad-2 and Smad-4 gene expression levels. These results indicated that Rutin exerted a negative regulatory effect on hepatotoxicity and fibrogenesis. TGF- $\beta 1 /$ Smad pathway 


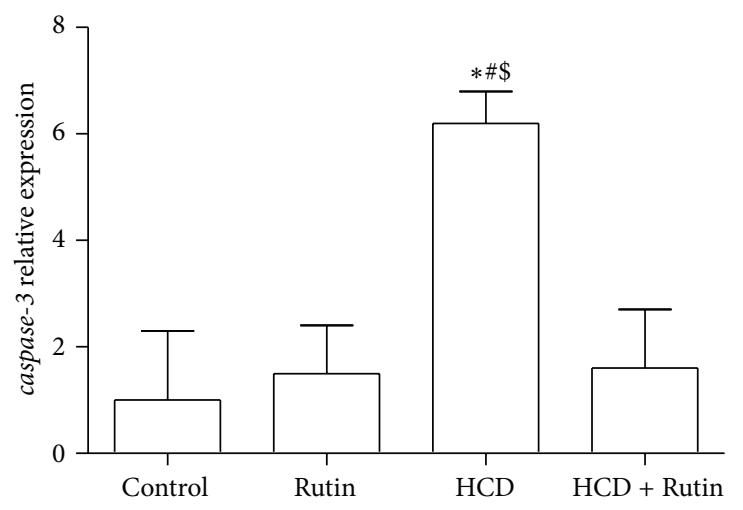

(a)

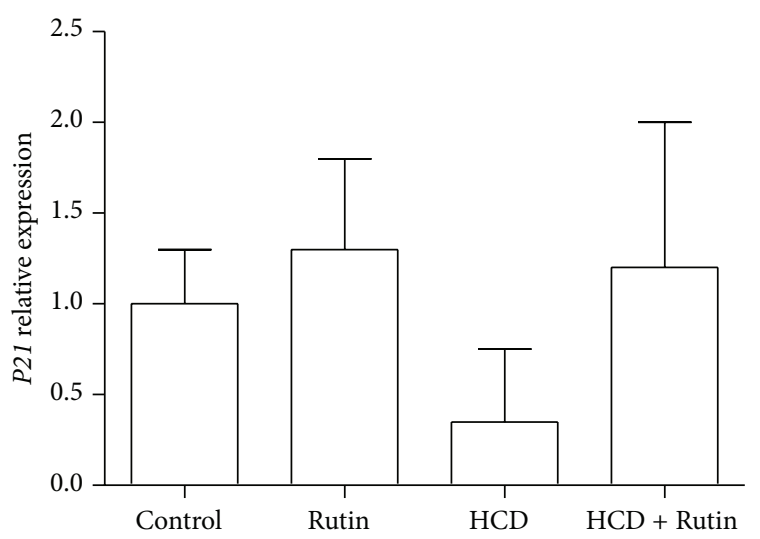

(c)

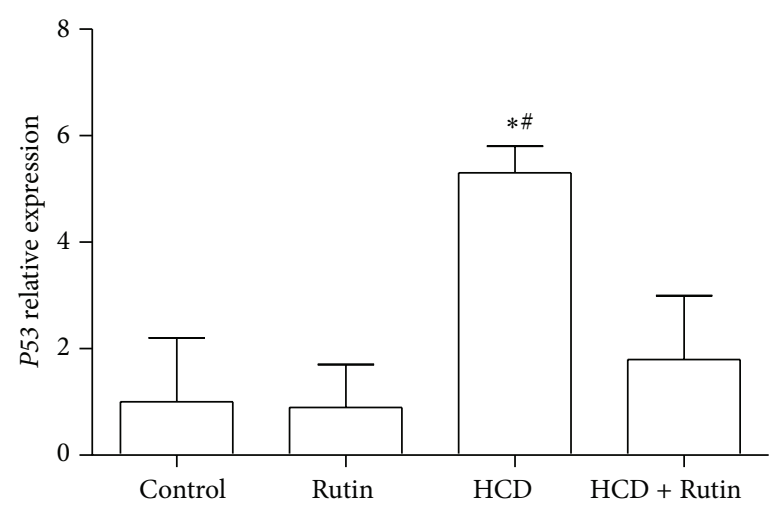

(b)

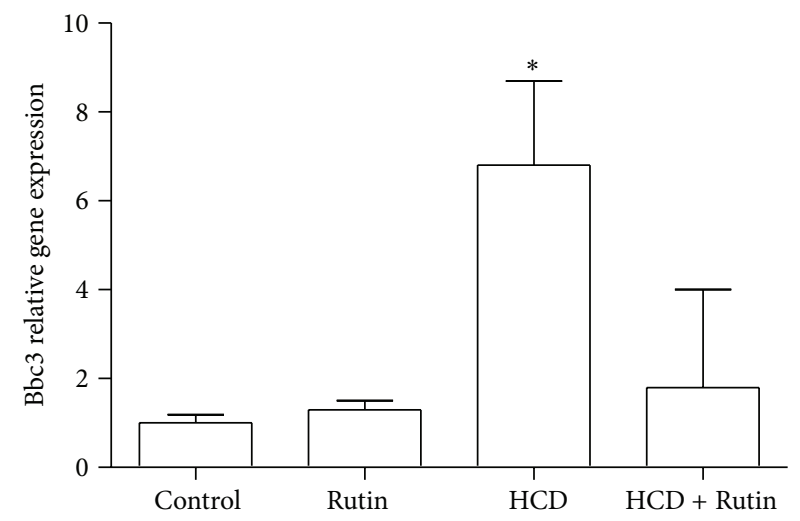

(d)

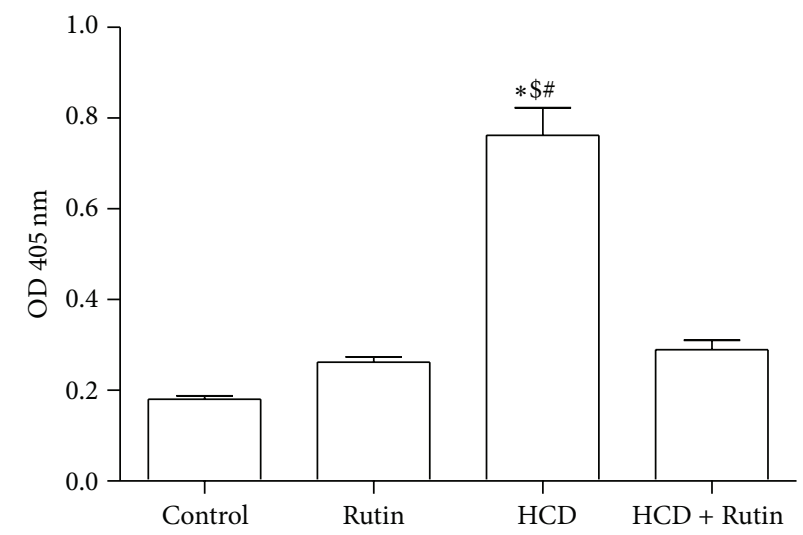

(e)

Figure 5: The effect of HCD, Rutin, and their combination on the expression levels of caspase-3 (a), P53 (b), P21 (c), Bbc3 (d), and cleavage caspase-3 (e) in rat liver tissues. Data are presented as mean $\pm \operatorname{SEM}(n=10) . *$, \#, and $\$$ indicate significant change from control, Rutin, and HCD plus Rutin, respectively, at $P<0.05$ using ANOVA followed by Tukey-Kramer as a post-ANOVA test.

and $I L-6$ are extensively studied as mutagenic and fibrotic factors and appear to be critical for matrix-producing cells activation. TGF- $\beta 1$ is a fibrosis mediator, which can enhance extracellular matrix deposition by activating stellate cells to turn on fibrosis gene expression and by inhibiting collagenase activity via Smad-2/-3 signaling [26]. Thus, they might be used in liver fibrosis treatment.

Tumor suppressor gene P53 plays a central role in fatty liver disease [80-82] and its activation may be important in fatty liver pathogenesis that facilitates apoptosis, oxidative stress, steatosis, and injury. The regulatory control of P53 appears to fail in fatty liver disease [83] as a direct downstream target of $P 53$ [84]. In the current study, HCD increases P53 expression level. This increase in P53 expression level in HCD may suggest that P53 activation may be involved in liver injury. This finding was in agreement with another study that found a positive correlation between steatosis and P53 expression in human liver samples [80]. 


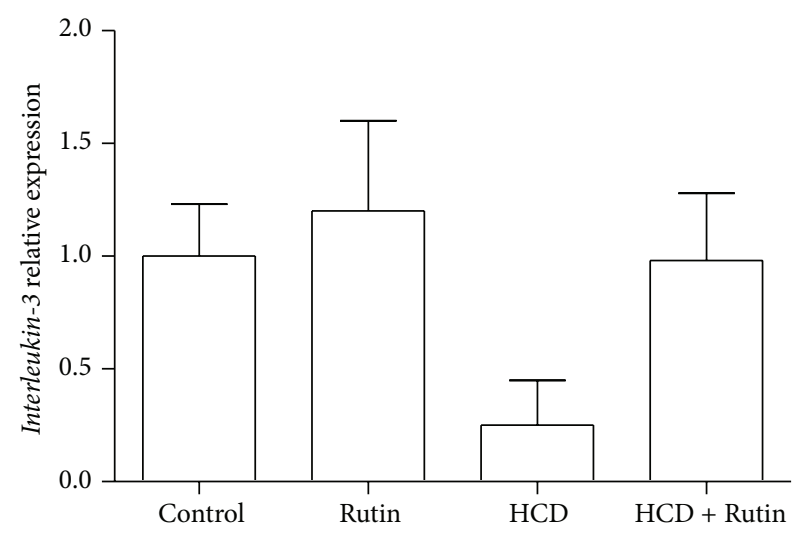

(a)

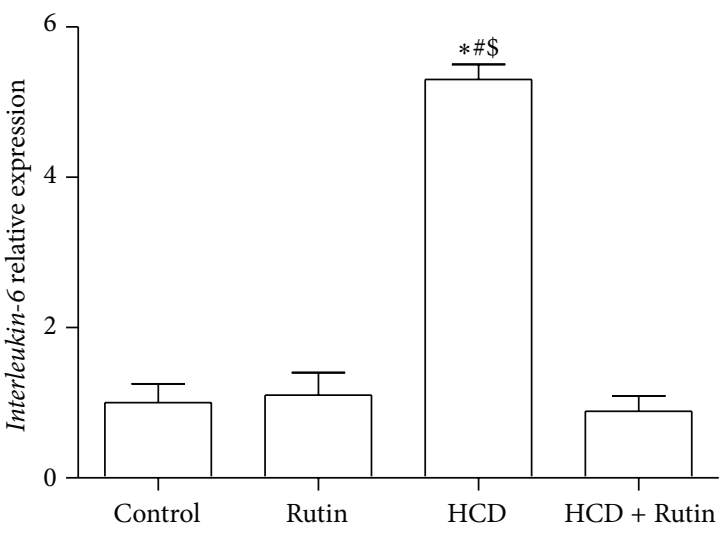

(b)

FIGURE 6: The effect of HCD, Rutin, and their combination on the expression levels of Interleukin-3 (a) and Interleukin-6 (b) in rat liver tissues. Data are presented as mean \pm SEM $(n=10) . *$, , and $\$$ indicate significant change from control, Rutin, and HCD plus Rutin, respectively, at $P<0.05$ using ANOVA followed by Tukey-Kramer as a post-ANOVA test.

Increases in the P53 expression induce CTGF result in liver fibrosis in rodent and human [85]. In the current study, the increase in the expression levels of $P 53$ is associated with increase in the expression of $B b c 3 . B b c 3$ interacts with antiapoptotic Bcl-2 family members such as $B c l-x L, B c l-2$, $M c l-1, B c l-w$, and $A 1$, inhibiting their interaction with $B a x$ and Bak which leads to release of apoptosis-inducing factor and mitochondrial apoptotic proteins cytochrome $\mathrm{c}$ leading to caspase activation and cell death [86].

The stage of liver steatosis increased the expression of $P 53$, in hepatocytes. Levels of $P 21$ often determine the cellular response to different stress induced by drug and others. In the current study, HCD induce reduction in the expression level of $P 21$. Reduction of endogenous $P 21$ expression attenuates the growth arrest and promotes cell death. Similarly, another study reported that the reduction in the expression level of P21 in MCF7 cells by antisense P21 RNA attenuates the growth arrest and promotes cell death [87]. Different types of cellular stress lead to induction of $P 21$ expression by both $P 53$ dependent and -independent mechanisms. High expression of $P 21$-induced growth arrest can protect cells from apoptosis. However, $P 21$ possesses proapoptotic functions and may play an active role in apoptosis induced by activation of members of the TNF family of death receptors. Activated $T N F \alpha / C D 95$ interacts with one or several cell surface receptors to trigger caspase activation and cytochrome $c$ release. In the current study HCD induce activation of caspase-3. Caspase-3mediated cleavage of $P 21$ and subsequent upregulation of cyclin A/Cdk2 activity is considered an important mechanism for death associated with cyclin A/Cdk2 activation in different cell types.

During hepatic injury, induced by oxidative stress, the HO-1 and Nrf2 expression levels were downregulated and were associated with upregulation in $N F-\kappa B[33,34]$. Overexpression of these transcription factors acts to promote apoptosis. The Rutin administration increased $\mathrm{Nrf2}$ and $\mathrm{HO}$ 1 expression levels and suppressed the expression levels of $N F-\kappa B$. In addition to oxidative stress, high-cholesterol diet decreases the expression levels of genes involved in muscle mitochondrial biogenesis and function, such as Sirt1 [39]. The mechanisms of liver apoptosis in NAFLD induced by HCD need more study to understand the mechanism.

\section{Conclusion}

In conclusion, our findings demonstrated that Rutin could lower and attenuate hepatotoxicity induced by HCD in rat model. Signaling molecules in the TGF- $\beta /$ Smad signaling pathway were restored to nearly their normal levels. Considering its excellent safety profile, we propose that Rutin could be used in people at high risk of developing hepatotoxicity induced by HCD.

\section{Competing Interests}

The authors declare that they have no competing interests.

\section{Acknowledgments}

The authors extend their appreciation to the Deanship of Scientific Research at King Saud University for funding this work through Research Project no. NFG-14-02-13.

\section{References}

[1] J. M. Clark, "The epidemiology of nonalcoholic fatty liver disease in adults," Journal of Clinical Gastroenterology, vol. 40, no. 1, pp. S5-S10, 2006.

[2] J. P. Ong and Z. M. Younossi, "Epidemiology and natural history of NAFLD and NASH," Clinics in Liver Disease, vol. 11, no. 1, pp. $1-16,2007$.

[3] M. Lazo and J. M. Clark, "The epidemiology of nonalcoholic fatty liver disease: a global perspective," Seminars in Liver Disease, vol. 28, no. 4, pp. 339-350, 2008.

[4] J.-G. Fan and G. C. Farrell, "Epidemiology of non-alcoholic fatty liver disease in China," Journal of Hepatology, vol. 50, no. 1, pp. 204-210, 2009. 
[5] A. St George, A. Bauman, A. Johnston, G. Farrell, T. Chey, and J. George, "Independent effects of physical activity in patients with nonalcoholic fatty liver disease," Hepatology, vol. 50, no. 1, pp. 68-76, 2009.

[6] L. Gan, S. Chitturi, and G. C. Farrell, "Mechanisms and implications of age-related changes in the liver: nonalcoholic fatty liver disease in the elderly," Current Gerontology and Geriatrics Research, vol. 2011, Article ID 831536, 12 pages, 2011.

[7] J. Manchanayake, S. Chitturi, C. Nolan, and G. C. Farrell, "Postprandial hyperinsulinemia is universal in non-diabetic patients with nonalcoholic fatty liver disease," Journal of Gastroenterology and Hepatology, vol. 26, no. 3, pp. 510-516, 2011.

[8] J.-G. Fan, "Epidemiology of alcoholic and nonalcoholic fatty liver disease in China," Journal of Gastroenterology and Hepatology, vol. 28, supplement 1, pp. 11-17, 2013.

[9] G. C. Farrell and C. Z. Larter, "Nonalcoholic fatty liver disease: from steatosis to cirrhosis," Hepatology, vol. 43, no. 2, supplement 1, pp. S99-S112, 2006.

[10] S. S. Al-Rejaie, A. M. Aleisa, M. M. Sayed-Ahmed et al., "Protective effect of rutin on the antioxidant genes expression in hypercholestrolemic male Westar rat," BMC Complementary and Alternative Medicine, vol. 13, article no. 136, 2013.

[11] B. Wang, J. Sun, Y. Ma, G. Wu, Y. Shi, and G. Le, "Increased oxidative stress and the apoptosis of regulatory $\mathrm{T}$ cells in obese mice but not resistant mice in response to a high-fat diet," Cellular Immunology, vol. 288, no. 1-2, pp. 39-46, 2014.

[12] A. E. Feldstein, A. Canbay, P. Angulo et al., "Hepatocyte apoptosis and Fas expression are prominent features of human nonalcoholic steatohepatitis," Gastroenterology, vol. 125, no. 2, pp. 437-443, 2003.

[13] P. S. Ribeiro, H. Cortez-Pinto, S. Solá et al., "Hepatocyte apoptosis, expression of death receptors, and activation of NF$\kappa \mathrm{B}$ in the liver of nonalcoholic and alcoholic steatohepatitis patients," American Journal of Gastroenterology, vol. 99, no. 9, pp. 1708-1717, 2004.

[14] A. E. Feldstein and G. J. Gores, "Apoptosis in alcoholic and nonalcoholic steatohepatitis," Frontiers in Bioscience, vol. 10, no. 3, pp. 3093-3099, 2005.

[15] M. E. Guicciardi and G. J. Gores, "Apoptosis: a mechanism of acute and chronic liver injury," Gut, vol. 54, no. 7, pp. 1024-1033, 2005.

[16] H. Kayadibi, E. Sertoglu, and M. Uyanik, "Which diagnostic tool for the prediction of intermediate liver fibrosis stages?" European Journal of Gastroenterology and Hepatology, vol. 27, no. 2, p. 182, 2015.

[17] C. F. Subasi, U. E. Aykut, and Y. Yilmaz, "Comparison of noninvasive scores for the detection of advanced fibrosis in patients with nonalcoholic fatty liver disease," European Journal of Gastroenterology and Hepatology, vol. 27, no. 2, pp. 137-141, 2015.

[18] A. Canbay, S. Friedman, and G. J. Gores, "Apoptosis: the nexus of liver injury and fibrosis," Hepatology, vol. 39, no. 2, pp. 273278, 2004.

[19] T. Takehara, T. Tatsumi, T. Suzuki et al., "Hepatocyte-specific disruption of Bcl-x L leads to continuous hepatocyte apoptosis and liver fibrotic responses," Gastroenterology, vol. 127, no. 4, pp. 1189-1197, 2004.

[20] A. Canbay, P. Taimr, N. Torok, H. Higuchi, S. Friedman, and G. J. Gores, "Apoptotic body engulfment by a human stellate cell line is profibrogenic," Laboratory Investigation, vol. 83, no. 5, pp. 655-663, 2003.
[21] A. Watanabe, A. Hashmi, D. A. Gomes et al., "Apoptotic hepatocyte DNA inhibits hepatic stellate cell chemotaxis via toll-like receptor 9," Hepatology, vol. 46, no. 5, pp. 1509-1518, 2007.

[22] Y. Shi and J. Massagué, "Mechanisms of TGF- $\beta$ signaling from cell membrane to the nucleus," Cell, vol. 113, no. 6, pp. 685-700, 2003.

[23] G. Euler-Taimor and J. Heger, "The complex pattern of SMAD signaling in the cardiovascular system," Cardiovascular Research, vol. 69, no. 1, pp. 15-25, 2006.

[24] D. Schneiders, J. Heger, P. Best, H. M. Piper, and G. Taimor, "SMAD proteins are involved in apoptosis induction in ventricular cardiomyocytes," Cardiovascular Research, vol. 67, no. 1, pp. 87-96, 2005.

[25] B. Wang, J. Hao, S. C. Jones, M.-S. Yee, J. C. Roth, and I. M. C. Dixon, "Decreased Smad 7 expression contributes to cardiac fibrosis in the infarcted rat heart," American Journal of Physiology-Heart and Circulatory Physiology, vol. 282, no. 5, pp. H1685-H1696, 2002.

[26] W. Huang, L. Li, X. Tian et al., "Astragalus and Paeoniae radix rubra extract inhibits liver fibrosis by modulating the transforming growth factor $\beta /$ Smad pathway in rats," Molecular Medicine Reports, vol. 11, no. 2, pp. 805-814, 2015.

[27] H. Herbst, T. Wege, S. Milani et al., "Tissue inhibitor of metalloproteinase-1 and -2 RNA expression in rat and human liver fibrosis," The American Journal of Pathology, vol. 150, no. 5, pp. 1647-1659, 1997.

[28] N. Nieto, J. A. Dominguez-Rosales, L. Fontana et al., "Rat hepatic stellate cells contribute to the acute-phase response with increased expression of $\alpha 1$ (I) and $\alpha 1$ (IV) collagens, tissue inhibitor of metalloproteinase-1, and matrixmetalloproteinase-2 messenger RNAs," Hepatology, vol. 33, no. 3, pp. 597-607, 2001.

[29] S. Kurita, K. Takeuchi, Y. Hayashi et al., "Significance of serum Zn- $\alpha 2$-glycoprotein for the regulation of blood pressure," Hypertension Research, vol. 38, no. 4, pp. 244-251, 2015.

[30] S. Dooley, J. Hamzavi, L. Ciuclan et al., "Hepatocyte-specific Smad7 expression attenuates TGF- $\beta$-mediated fibrogenesis and protects against liver damage," Gastroenterology, vol. 135, no. 2, pp. 642-659, 2008.

[31] G. Sass, R. Barikbin, and G. Tiegs, "The multiple functions of heme oxygenase-1 in the liver," Zeitschrift für Gastroenterologie, vol. 50, no. 1, pp. 34-40, 2012.

[32] Y.-C. Yang, C.-K. Lii, A.-H. Lin et al., "Induction of glutathione synthesis and heme oxygenase 1 by the flavonoids butein and phloretin is mediated through the ERK/Nrf2 pathway and protects against oxidative stress," Free Radical Biology and Medicine, vol. 51, no. 11, pp. 2073-2081, 2011.

[33] Y. H. Choi, “The cytoprotective effect of isorhamnetin against oxidative stress is mediated by the upregulation of the Nrf2dependent $\mathrm{HO}-1$ expression in $\mathrm{C} 2 \mathrm{C} 12$ myoblasts through scavenging reactive oxygen species and ERK inactivation," General Physiology and Biophysics, 2016.

[34] Y. H. Choi, "The cytoprotective effects of ethanol extract of Ecklonia cava against oxidative stress are associated with upregulation of Nrf2-mediated HO-1 and NQO-1 expression through activation of the MAPK pathway," General Physiology and Biophysics, vol. 35, no. 1, pp. 45-53, 2016.

[35] R. Acquaviva, R. Lanteri, G. Li Destri et al., "Beneficial effects of rutin and $\mathrm{L}$-arginine coadministration in a rat model of liver ischemia-reperfusion injury," American Journal of PhysiologyGastrointestinal and Liver Physiology, vol. 296, no. 3, pp. G664G670, 2009. 
[36] Q. Lin, S. Weis, G. Yang et al., "Heme oxygenase-1 protein localizes to the nucleus and activates transcription factors important in oxidative stress," The Journal of Biological Chemistry, vol. 282, no. 28, pp. 20621-20633, 2007.

[37] T. Lawrence, "The nuclear factor NF-kappaB pathway in inflammation," Cold Spring Harbor Perspectives in Biology, vol. 1, no. 6, Article ID a001651, 2009.

[38] J. T. Rodgers, C. Lerin, W. Haas, S. P. Gygi, B. M. Spiegelman, and P. Puigserver, "Nutrient control of glucose homeostasis through a complex of PGC- $1 \alpha$ and SIRT1," Nature, vol. 434, no. 7029, pp. 113-118, 2005.

[39] R. Bergeron, J. M. Ren, K. S. Cadman et al., "Chronic activation of AMP kinase results in NRF-1 activation and mitochondrial biogenesis," American Journal of Physiology-Endocrinology and Metabolism, vol. 281, no. 6, pp. E1340-E1346, 2001.

[40] S. Seo, M.-S. Lee, E. Chang et al., "Rutin increases muscle mitochondrial biogenesis with AMPK activation in high-fat diet-induced obese rats," Nutrients, vol. 7, no. 9, pp. 8152-8169, 2015.

[41] J. D. Potter, "Cancer prevention: epidemiology and experiment," Cancer Letters, vol. 114, no. 1-2, pp. 7-9, 1997.

[42] P. N. Aleksandrov, T. V. Speranskaia, G. Bobkov Iu, V. A. Zagorevskii, and D. A. Zykov, "Effect of rutin and esculamine on models of aseptic inflammation," Farmakologiia i Toksikologiia, vol. 49, no. 1, pp. 84-86, 1986.

[43] E. E. Deschner, J. Ruperto, G. Wong, and H. L. Newmark, "Quercetin and rutin as inhibitors of azoxymethanol-induced colonic neoplasia," Carcinogenesis, vol. 12, no. 7, pp. 1193-1196, 1991.

[44] A. López-Revuelta, J. I. Sánchez-Gallego, A. HernándezHernández, J. Sánchez-Yagüe, and M. Llanillo, "Membrane cholesterol contents influence the protective effects of quercetin and rutin in erythrocytes damaged by oxidative stress," Chemico-Biological Interactions, vol. 161, no. 1, pp. 79-91, 2006.

[45] S. M. Artham, C. J. Lavie, R. V. Milani, and H. O. Ventura, "The obesity paradox: impact of obesity on the prevalence and prognosis of cardiovascular diseases," Postgraduate Medicine, vol. 120, no. 2, pp. 34-41, 2008.

[46] S. Bellentani, G. Saccoccio, F. Masutti et al., "Prevalence of and risk factors for hepatic steatosis in northern Italy," Annals of Internal Medicine, vol. 132, no. 2, pp. 112-117, 2000.

[47] P. Vitaglione, F. Morisco, G. Mazzone et al., "Coffee reduces liver damage in a rat model of steatohepatitis: the underlying mechanisms and the role of polyphenols and melanoidins," Hepatology, vol. 52, no. 5, pp. 1652-1661, 2010.

[48] S. K. Das, V. Balakrishnan, S. Mukherjee, and D. M. Vasudevan, "Evaluation of blood oxidative stress-related parameters in alcoholic liver disease and non-alcoholic fatty liver disease," Scandinavian Journal of Clinical and Laboratory Investigation, vol. 68, no. 4, pp. 323-334, 2008.

[49] H.-Y. Song, Z.-M. Mao, L.-L. Yang et al., "Dangfei liganning capsules attenuate the susceptibility of rat nonalcoholic fatty liver to carbon tetrachloride toxicity," Journal of Traditional Chinese Medicine, vol. 31, no. 4, pp. 327-333, 2011.

[50] N. Kamalakkannan and P. S. M. Prince, "Antihyperglycaemic and antioxidant effect of rutin, a polyphenolic flavonoid, in streptozotocin-induced diabetic wistar rats," Basic and Clinical Pharmacology and Toxicology, vol. 98, no. 1, pp. 97-103, 2006.

[51] J. Halcox and A. Misra, "Type 2 diabetes mellitus, metabolic syndrome, and mixed dyslipidemia: how similar, how different, and how to treat?" Metabolic Syndrome and Related Disorders, vol. 13, no. 1, pp. 1-21, 2015.
[52] Y.-W. Fu and H.-B. He, "Apoptosis of periodontium cells in streptozototocin- and ligature-induced experimental diabetic periodontitis in rats," Acta Odontologica Scandinavica, vol. 71, no. 5, pp. 1206-1215, 2013.

[53] K. N. Otwombe, F. Laher, T. Tutu-Gxashe, G. Gray, and L. Mohapi, "The effect of a maturing antiretroviral program on early mortality for patients with advanced immune-suppression in Soweto, South Africa," PLoS ONE, vol. 8, no. 11, Article ID e81538, 2013.

[54] A. Dasgupta, J. Zheng, N. I. Perrone-Bizzozero, and O. A. Bizzozero, "Increased carbonylation, protein aggregation and apoptosis in the spinal cord of mice with experimental autoimmune encephalomyelitis," ASN neuro, vol. 5, no. 1, Article ID e00111, 2013.

[55] S. Arumugam, S. Mito, R. A. Thandavarayan et al., "Mulberry leaf diet protects against progression of experimental autoimmune myocarditis to dilated cardiomyopathy via modulation of oxidative stress and MAPK-mediated apoptosis," Cardiovascular Therapeutics, vol. 31, no. 6, pp. 352-362, 2013.

[56] F. Bayatli, D. Akkuş, E. Kilic, R. Saraymen, and M. F. Sönmez, "The protective effects of grape seed extract on MDA, AOPP, apoptosis and eNOS expression in testicular torsion: an experimental study," World Journal of Urology, vol. 31, no. 3, pp. 615622, 2013.

[57] D. A. Papanicolaou, R. L. Wilder, S. C. Manolagas, and G. P. Chrousos, "The pathophysiologic roles of interleukin- 6 in human disease," Annals of Internal Medicine, vol. 128, no. 2, pp. 127-137, 1998.

[58] A. J. Thompson, A. J. Muir, M. S. Sulkowski et al., "Interleukin28B polymorphism improves viral kinetics and is the strongest pretreatment predictor of sustained virologic response in genotype 1 Hepatitis C virus," Gastroenterology, vol. 139, no. 1, pp. 120-129.e18, 2010.

[59] R. Valentino, V. D’Esposito, F. Passaretti et al., "Bisphenol-A impairs insulin action and up-regulates inflammatory pathways in human subcutaneous adipocytes and 3T3-L1 cells," PLoS ONE, vol. 8, no. 12, Article ID e82099, 2013.

[60] X. B. Cui, Y.Z. Chen, and F. Li, "Recent advances on relationship between phospholipase C epsilon-1 gene and tumor," Zhonghua Bing Li Xue Za Zhi, vol. 41, no. 3, pp. 213-216, 2012.

[61] S. K. Das and V. Balakrishnan, "Role of cytokines in the pathogenesis of non-alcoholic fatty liver disease," Indian Journal of Clinical Biochemistry, vol. 26, no. 2, pp. 202-209, 2011.

[62] M.-D. Jiang, H.-D. Ma, X.-F. Zhong, F.-W. Xie, and W.-Z. Zeng, "Effects of Erk signal transduction on the cell cycle of rat hepatic stellate cells stimulated by acetaldehyde," Zhonghua Gan Zang Bing Za Zhi, vol. 11, no. 11, pp. 650-653, 2003.

[63] B. Saile, C. Eisenbach, H. El-Armouche, K. Neubauer, and G. Ramadori, "Antiapoptotic effect of interferon- $\alpha$ on hepatic stellate cells (HSC): a novel pathway of IFN- $\alpha$ signal transduction via Janus kinase 2 (JAK 2) and caspase-8," European Journal of Cell Biology, vol. 82, no. 1, pp. 31-41, 2003.

[64] M. A. Ganaie, T. H. Khan, N. A. Siddiqui, and M. N. Ansari, "Ameliorative effect of methanol extract of Rumex vesicarius on $\mathrm{CCl}_{4}$-induced liver damage in Wistar albino rats," Pharmaceutical Biology, vol. 53, no. 8, pp. 1163-1167, 2015.

[65] M. Peters, K.-H. Meyer zum Büschenfelde, and S. Rose-John, "The function of the soluble IL-6 receptor in vivo," Immunology Letters, vol. 54, no. 2-3, pp. 177-184, 1996.

[66] D. Novick, H. Engelmann, D. Wallach, and M. Rubinstein, "Soluble cytokine receptors are present in normal human urine," 
Journal of Experimental Medicine, vol. 170, no. 4, pp. 1409-1414, 1989.

[67] M. Honda, S. Yamamoto, M. Cheng et al., "Human soluble IL-6 receptor: its detection and enhanced release by HIV infection," Journal of Immunology, vol. 148, no. 7, pp. 2175-2180, 1992.

[68] S. S. Edranov and P. A. Motavkin, "Apoptosis as a mechanism of maxillary sinus mucosa injury in rats after experimental transection of the maxillary nerve," Bulletin of Experimental Biology and Medicine, vol. 153, no. 4, pp. 526-529, 2012.

[69] T. Kauss, D. Moynet, J. Rambert et al., "Rutoside decreases human macrophage-derived inflammatory mediators and improves clinical signs in adjuvant-induced arthritis," Arthritis Research and Therapy, vol. 10, no. 1, article R19, 2008.

[70] M. Eder, G. Geissler, and A. Ganser, "IL-3 in the clinic," Stem Cells, vol. 15, no. 5, pp. 327-333, 1997.

[71] D. E. Johnson, "Regulation of survival pathways by IL-3 and induction of apoptosis following IL-3 withdrawal," Frontiers in Bioscience, vol. 3, pp. d313-d324, 1998.

[72] H. Bessler, M. Bergman, and H. Salman, "Interleukin-3 and stress," Biomedicine and Pharmacotherapy, vol. 54, no. 6, pp. 299-304, 2000.

[73] X.-G. Zhang, P. Xu, Q. Liu et al., "Effect of tea polyphenol on cytokine gene expression in rats with alcoholic liver disease," Hepatobiliary and Pancreatic Diseases International, vol. 5, no. 2, pp. 268-272, 2006.

[74] Y. Sheng, Y. Ma, Z. Deng, Z. Wang, and L. Ji, "Cytokines as potential biomarkers of liver toxicity induced by Dioscorea bulbifera L," Bioscience Trends, vol. 8, no. 1, pp. 32-37, 2014.

[75] R.-M. Liu and K. A. Gaston Pravia, "Oxidative stress and glutathione in TGF- $\beta$-mediated fibrogenesis," Free Radical Biology and Medicine, vol. 48, no. 1, pp. 1-15, 2010.

[76] J. Schmutzhard, R. Glueckert, C. Pritz et al., "Sepsis otopathy: experimental sepsis leads to significant hearing impairment due to apoptosis and glutamate excitotoxicity in murine cochlea," Disease Models \& Mechanisms, vol. 6, no. 3, pp. 745-754, 2013.

[77] J. Zhao, M. Zhang, and Y. Chen, "Experimental research on the mechanisms of human multiple myeloma LP-1 cell apoptosis induced by oridonin," Zhongguo Zhong Xi Yi Jie He Za Zhi, vol. 32, no. 12, pp. 1642-1646, 2012.

[78] S. Öksüz, E. Ülkür, O. Öncül, G. T. Köse, Z. Küçükodac, and M. Urhan, "The effect of subcutaneous mesenchymal stem cell injection on statis zone and apoptosis in an experimental burn model," Plastic and Reconstructive Surgery, vol. 131, no. 3, pp. 463-471, 2013.

[79] S. Velayuthaprabhu, H. Matsubayashi, T. Sugi et al., "Expression of apoptosis in placenta of experimental antiphospholipid syndrome mouse," American Journal of Reproductive Immunology, vol. 69, no. 5, pp. 486-494, 2013.

[80] A. Panasiuk, J. Dzieciol, B. Panasiuk, and D. Prokopowicz, "Expression of p53, Bax and Bcl-2 proteins in hepatocytes in non-alcoholic fatty liver disease," World Journal of Gastroenterology, vol. 12, no. 38, pp. 6198-6202, 2006.

[81] C. S. Lieber, M. A. Leo, X. Wang, and L. M. DeCarli, "Alcohol alters hepatic FoxO1, p53, and mitochondrial SIRT5 deacetylation function," Biochemical and Biophysical Research Communications, vol. 373, no. 2, pp. 246-252, 2008.

[82] N. Edebali, İ. Ö. Tekin, B. Açıkgöz et al., "Apoptosis and necrosis in the circumventricular organs after experimental subarachnoid hemorrhage as detected with annexin $\mathrm{V}$ and caspase 3 immunostaining," Neurological Research, vol. 36, no. 12, pp. 1114-1120, 2014.
[83] J. Lee, A. Padhye, A. Sharma et al., "A pathway involving farnesoid X receptor and small heterodimer partner positively regulates hepatic sirtuin 1 levels via MicroRNA-34a inhibition," Journal of Biological Chemistry, vol. 285, no. 17, pp. 12604-12611, 2010.

[84] H. Hermeking, "p53 enters the MicroRNA world," Cancer Cell, vol. 12, no. 5, pp. 414-418, 2007.

[85] T. Kodama, T. Takehara, H. Hikita et al., "Increases in p53 expression induce CTGF synthesis by mouse and human hepatocytes and result in liver fibrosis in mice," Journal of Clinical Investigation, vol. 121, no. 8, pp. 3343-3356, 2011.

[86] J. Vávrová and M. Řezáčová, “Importance of proapoptotic protein PUMA in cell radioresistance," Folia Biologica, vol. 60, no. 2, pp. 53-56, 2014.

[87] A. L. Gartel and A. L. Tyner, "The role of the cyclin-dependent kinase inhibitor p21 in apoptosis," Molecular Cancer Therapeutics, vol. 1, no. 8, pp. 639-649, 2002. 


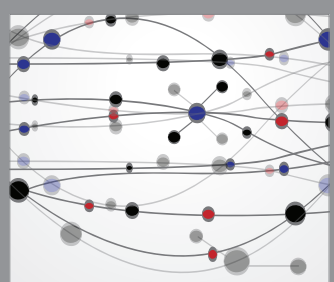

The Scientific World Journal
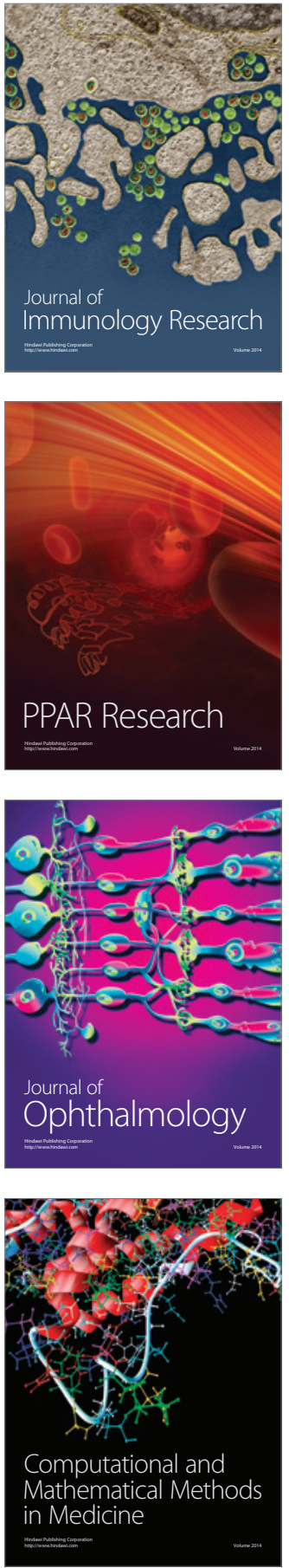

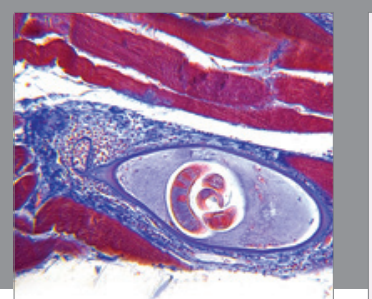

Gastroenterology Research and Practice

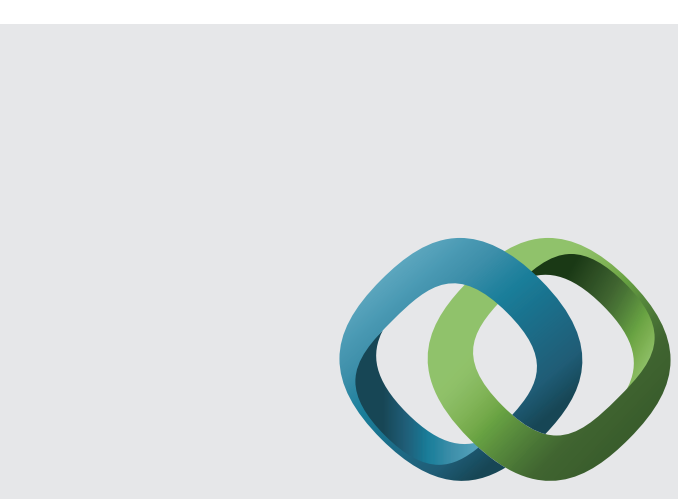

\section{Hindawi}

Submit your manuscripts at

http://www.hindawi.com
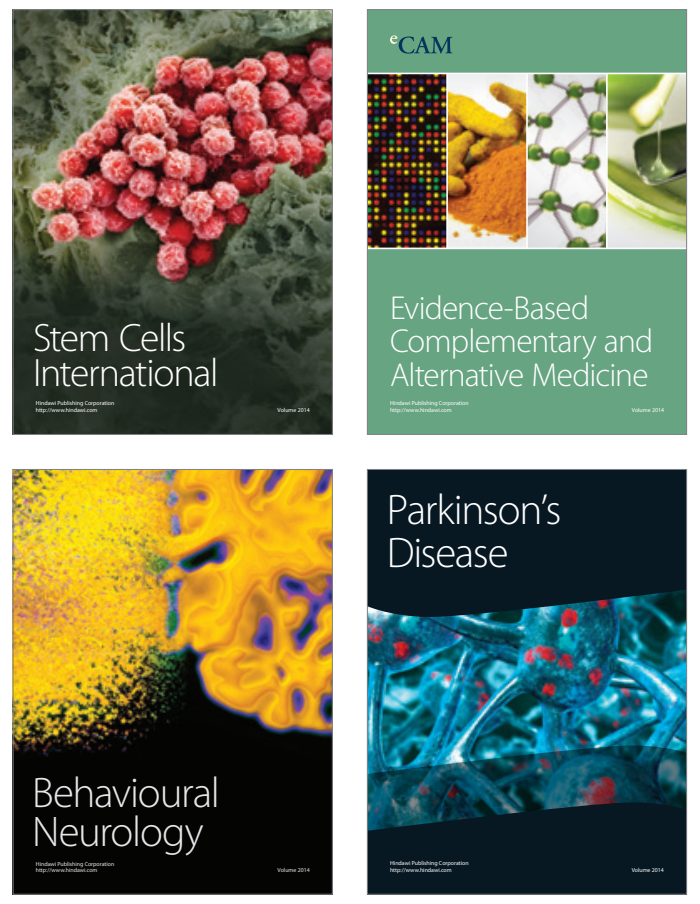
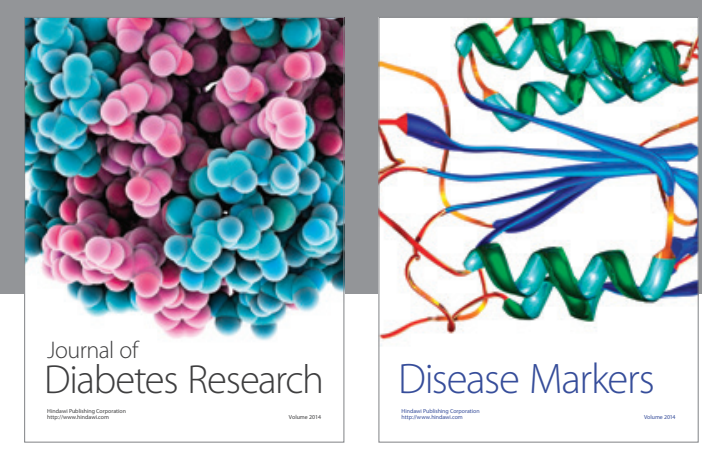

Disease Markers
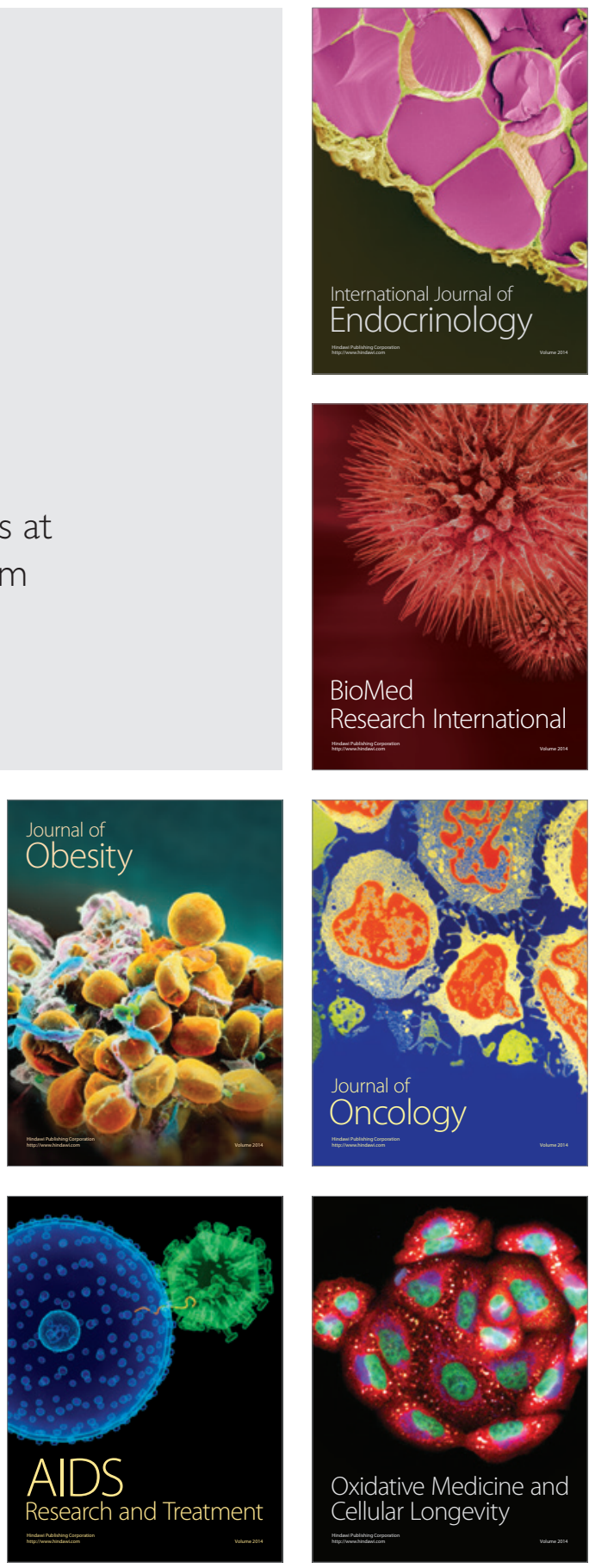